Bull. Mater. Sci., Vol. 21, No. 3, June 1998, pp. 241-245. (C) Indian Academy of Sciences.

\title{
Fracture toughness correlation with microstructure and other mechanical properties in near-eutectoid steel
}

\author{
K V SUDHAKAR* and G S MURTY \\ Department of Materials and Metallurgical Engineering, Indian Institute of Technology, Kanpur 208 016, India \\ *Present address: Department of Metallurgy, Indian Institute of Science, Bangalore 560 012, India
}

MS received 9 May 1997; revised 16 April 1998

\begin{abstract}
The variation of yield strength and fracture toughness was investigated for four different heat treatments attempted on specimens of a near-eutectoid steel. The aim of this study was to optimize the microstructure for simultaneous improvements in strength and toughness. Further, the fracture toughness deduced through empirical relations from tensile and charpy impact tests was compared with those measured directly according to ASTM Designation: E 399. Among the four different heat treatments attempted in this study, the plane strain condition was valid in the fracture toughness tests for (i) normalized and (ii) hardened and tempered $\left(500^{\circ} \mathrm{C}\right.$ for $\left.1 \mathrm{~h}\right)$ treatments only. The latter of the two heat treatments resulted in simultaneous improvement of strength and plane strain fracture toughness. The finely-dispersed carbides seem to arrest the crack propagation and also increase the strength. The pearlitic microstructure of the former leads to easy crack propagation along cementite platelets and/or cementite/ferrite interfaces. The nature of variation of empirically determined toughness values from tensile tests for different heat treatments is similar to that measured directly through fracture toughness tests, although the two sets of values do not match quantitatively. On the other hand, the toughness data deduced from charpy impact test is in close agreement with that evaluated directly from fracture toughness tests.
\end{abstract}

Keywords. Fracture toughness; near-eutectoid steel; mechanical properties; heat treatment.

\section{Introduction}

One of the requirements of designing engineering structures is to enhance the load-bearing capacity without plastic yielding of the components. At the outset, it may appear that an increase in yield stress would meet this requirement. But it is not so because of increasing danger of brittle fracture in high strength materials. Simultaneous improvements in yield strength and fracture toughness are needed rather than either of them. While continuum mechanics is the basis of structural design, the control of mechanical properties of structural materials is in the realm of materials science requiring an understanding of the structure-property relations. Fracture toughness being a more complex property than the yield strength, the crucial issue requiring understanding is the effect of microstructure on crack propagation. This will provide solutions to problems like: (i) a systematic development of tougher alloys (alloy design), (ii) the inverse relationship between strength and toughness of a material, (iii) effect of heat treatment on toughness, and (iv) non-unique relation between strength and toughness. The variation in strength and fracture toughness for different microstructures in a near-eutectoid steel has been explored in this study. Further, the correlation between the fracture toughness measured directly and that deduced indirectly from other mechanical properties (obtained from tensile and impact tests) was also examined. The simpler test results may be availed to assess fracture toughness through such correlations.

\section{Experimental}

\subsection{Materials and heat treatment}

The chemical composition of the near-eutectoid steel used in this study is shown in table 1. Starting with hot-rolled plate of $12.5 \mathrm{~mm}$ thickness, various specimens for charpy, tensile and fracture toughness tests were machined according to the dimensions specified in figures

Table 1. Chemical composition of near-eutectoid steel.

\begin{tabular}{lcccccc}
\hline Element & $\mathrm{C}$ & $\mathrm{Si}$ & $\mathrm{Mn}$ & $\mathrm{S}$ & $\mathrm{P}$ & $\mathrm{Fe}$ \\
\hline$\% \mathrm{Wt}$. & 0.64 & 0.40 & 0.75 & 0.014 & 0.014 & Balance \\
\hline
\end{tabular}


1a-c. These specimens were coated with a ceramic slurry prior to heat treatment in order to minimize oxidation and decarburization. Four different heat treatments were attempted on these specimens in such a way that their strength and toughness varied with some overlap in their range. The heat treatment schedules for this purpose were selected from ASM handbook (from the listed properties for different heat treatments). The details of the adopted heat treatments are mentioned in table 2 .

\subsection{Fracture toughness test}

The fracture toughness tests were performed according to ASTM standard E399-83. Fafigue precracking and fracture toughness tests were carried out on an MTS 810 machine using three point bend test specimens.

Fatigue precracking was carried out by cyclically loading the notched specimens at a load ratio of 0.1 in load control mode. The maximum load of the fatigue cycle was chosen in such a way that the maximum stress intensity factor did not exceed $80 \%$ of the anticipated plane strain fracture toughness $\left(K_{\mathrm{IC}}\right)$ in each case. The precracked specimens were loaded monotonically in stroke controlled mode till fracture. From the recorded load

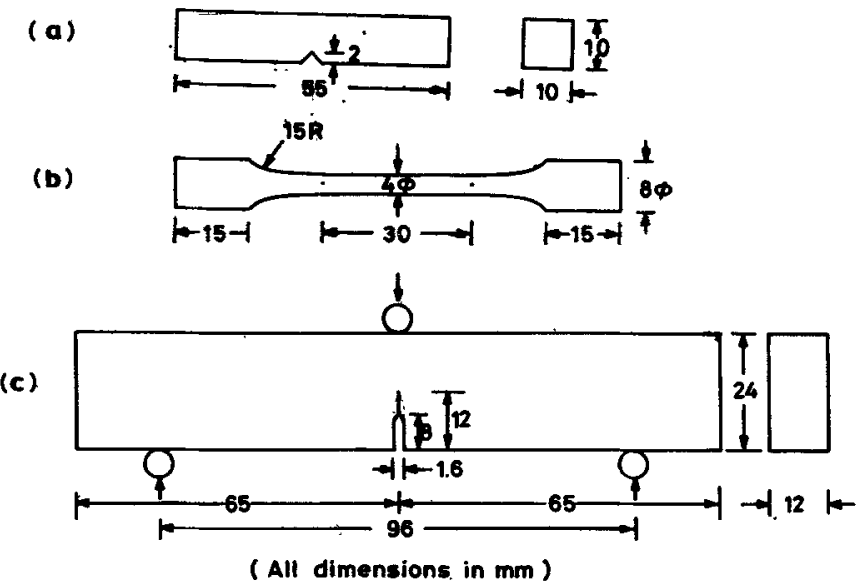

Figure 1. (a) Charpy test specimen, (b) tensile test specimen and (c) three-point bend test specimen. versus crack opening displacement (COD) data, the apparent fracture toughness $\left(K_{\mathrm{Q}}\right)$ was calculated using the relation:

$$
K_{\mathrm{Q}}=\left[P_{\mathrm{Q}} S / B W^{3 / 2}\right] f(a / W),
$$

where $P_{\mathrm{Q}}$ is the load corresponding to $2 \%$ crack extension (obtained through the intersection of $5 \%$ secant line), $S$ the span length, $B$ the thickness, $W$ the specimen width, $a$ the crack length and $f(a / W)$ is the specimen geometry and crack length related correction factor (known as $\mathrm{Y}$ factor), which is obtained analytically from the appropriate relations (ASTM E399; Provan 1988). The validity of plane strain condition is assessed by comparing the specimen thickness with $2.5\left(K_{\mathrm{Q}} / \sigma_{\mathrm{YS}}\right)^{2}$, where $\sigma_{\mathrm{YS}}$ is the $0.2 \%$ yield stress in uniaxial tension.

\subsection{Charpy and tensile tests}

The impact energy $C_{\mathrm{v}}$ (energy/unit area) of the standard charpy impact test is converted to equivalent $K_{\mathrm{Q}} / K_{\mathrm{IC}}$ making use of an empirical relation (Rolfe and Novak 1970):

$$
K_{\mathrm{rC}}^{2} / E=0.22\left(C_{\mathrm{v}}\right)^{1.5},
$$

where $E$ is the elastic modulus in $\mathrm{MPa}, K_{\mathrm{IC}}$ the plane strain fracture toughness in MPa $\sqrt{m}, C_{\mathrm{v}}$ the charpy energy in MPa.m and the units of the constant are [1/MPa.m] $]^{0.5}$. Standard tensile tests were also performed on differently heat treated specimens using an Instron testing machine. Equivalent $K_{\mathrm{IC}}$ values were deduced through an empirical relation (Hahn and Rosenfield 1968):

$$
K_{\mathrm{IC}}=n\left(2 E \sigma_{\mathrm{Ys}} \varepsilon_{\mathrm{f}} / 3\right)^{1 / 2},
$$

where $n$ is the strain hardening exponent and $\varepsilon_{f}$ the fracture strain in uniaxial tension.

\section{Results and discussion}

\subsection{Strength and fracture toughness}

The tensile stress-strain curves and typical loaddisplacement (COD) curves of precracked specimens in

\begin{tabular}{|c|c|c|c|c|c|c|}
\hline $\begin{array}{l}\text { S1 } \\
\text { no. }\end{array}$ & Heat treatment ${ }^{+}$ & $\begin{array}{c}0.2 \% \text { YS } \\
(\mathrm{MPa})\end{array}$ & $\begin{array}{l}\text { UTS } \\
\text { (MPa) }\end{array}$ & $\begin{array}{l}\text { Elong. } \\
(\%)\end{array}$ & $\begin{array}{l}\text { RA } \\
(\%)\end{array}$ & $\begin{array}{c}\text { Equivalent } \\
\text { fracture toughness } \\
K_{\mathrm{IC}}^{*}(\mathrm{MPa} \sqrt{m})\end{array}$ \\
\hline 1. & Normalized & 700 & 1060 & $19 \cdot 1$ & $36 \cdot 0$ & $30 \cdot 2$ \\
\hline 2. & $\begin{array}{l}\text { Oil hardened and tempered } \\
\text { at } 680^{\circ} \mathrm{C} \text { for } 1 \mathrm{~h}\end{array}$ & 700 & 780 & $23 \cdot 8$ & $58 \cdot 4$ & $41 \cdot 2$ \\
\hline 3. & Furnace cooled & 520 & 912 & $23 \cdot 8$ & $36 \cdot 7$ & $34 \cdot 2$ \\
\hline 4. & $\begin{array}{l}\text { Oil hardened and tempered } \\
\text { at } 500^{\circ} \mathrm{C} \text { for } 1 \mathrm{~h}\end{array}$ & 1464 & 1568 & $7 \cdot 2$ & $16 \cdot 7$ & $38 \cdot 7$ \\
\hline
\end{tabular}
fracture toughness tests are presented in figures 2 and

Table 2. Tensile test data of heat treated specimens.

*Obtained from equation (3); ${ }^{+}$all austenitized at $860^{\circ} \mathrm{C}$. 
3 , respectively. The tensile yield strength and fracture toughness $\left(K_{\mathrm{Q}}\right)$ data of differently heat treated specimens are given in tables 2 and 3 . It is seen that the yield strength of normalized specimen and that tempered at $680^{\circ} \mathrm{C}$ for $1 \mathrm{~h}$ is the same. The specimen tempered at $500^{\circ} \mathrm{C}$ for $1 \mathrm{~h}$ exhibited the highest yield strength among all the heat treated specimens. It is well known that in a hardened steel, when heated successively to higher temperatures above room temperature, submicroscopic particles of cementite are formed through the gradual loss of excess carbon in martensite. With continued heating, the particles of cementite grow in size by a process of coalescence and growth. This coalescence is more pronounced at higher tempering temperature. The

Table 3. Fracture toughness test data of heat treated specimens.

\begin{tabular}{|c|c|c|c|c|c|}
\hline $\begin{array}{l}\text { Sl } \\
\text { no. }\end{array}$ & Heat treatment ${ }^{+}$ & $\begin{array}{l}\text { Crack length } \\
a(\mathrm{~mm})\end{array}$ & $P_{\max } / P_{\mathrm{Q}}$ & $\begin{array}{c}\text { Fracture } \\
\text { toughness }\left(K_{\mathrm{Q}}\right) \\
(\mathrm{MPa} \sqrt{m})\end{array}$ & $\begin{array}{l}0.2 \% \text { YS (MPa) } \\
\text { from tensile test }\end{array}$ \\
\hline 1. & Normalized & $12 \cdot 02$ & $1 \cdot 10$ & $47 \cdot 5$ & 700 \\
\hline 2. & $\begin{array}{l}\text { Oil hardened and tempered } \\
\text { at } 680^{\circ} \mathrm{C} \text { for } 1 \mathrm{~h}\end{array}$ & 12.08 & 1.09 & $84 \cdot 7$ & 700 \\
\hline 3. & Furnace cooled & 11.96 & 1.00 & $55 \cdot 2$ & 520 \\
\hline 4. & $\begin{array}{l}\text { Oil hardened and tempered } \\
\text { at } 500^{\circ} \mathrm{C} \text { for } 1 \mathrm{~h}\end{array}$ & $12 \cdot 06$ & 1.01 & $69 \cdot 0$ & 1464 \\
\hline
\end{tabular}

${ }^{+}$All austenitized at $860^{\circ} \mathrm{C}$.

(a)

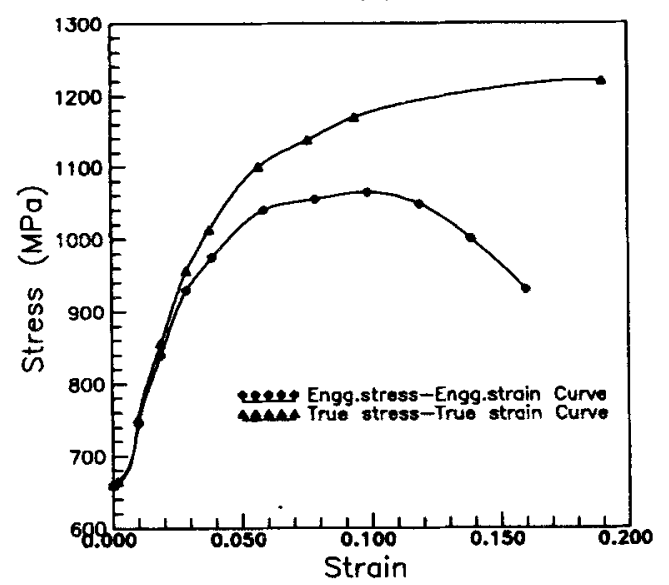

(c)

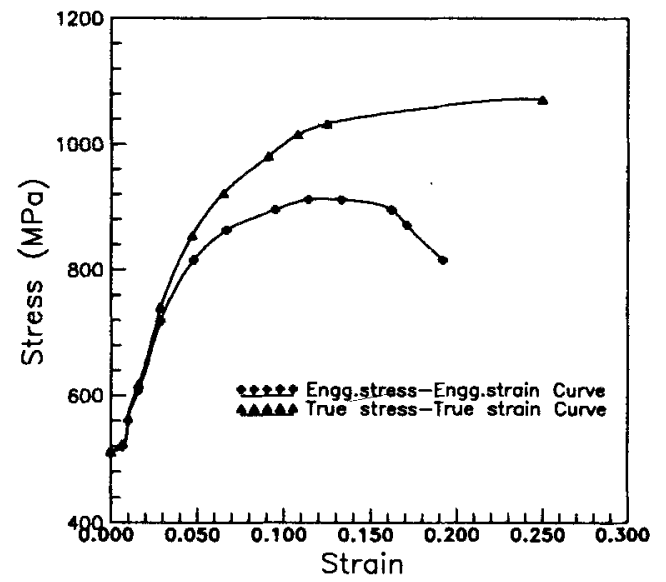

(b)

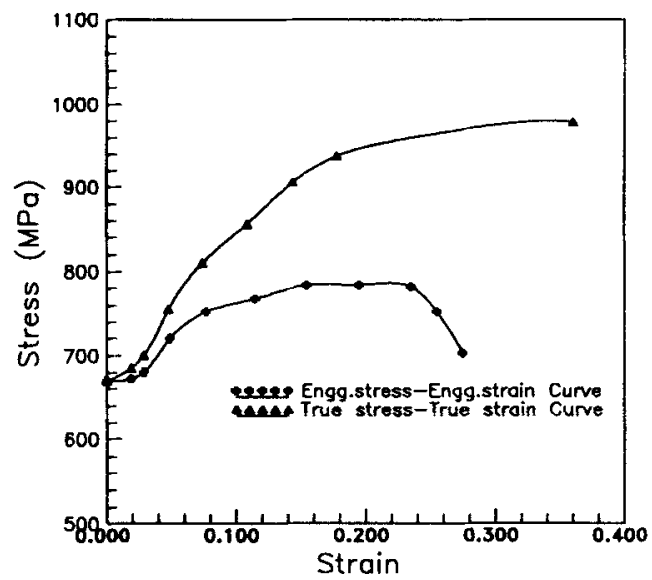

(d)

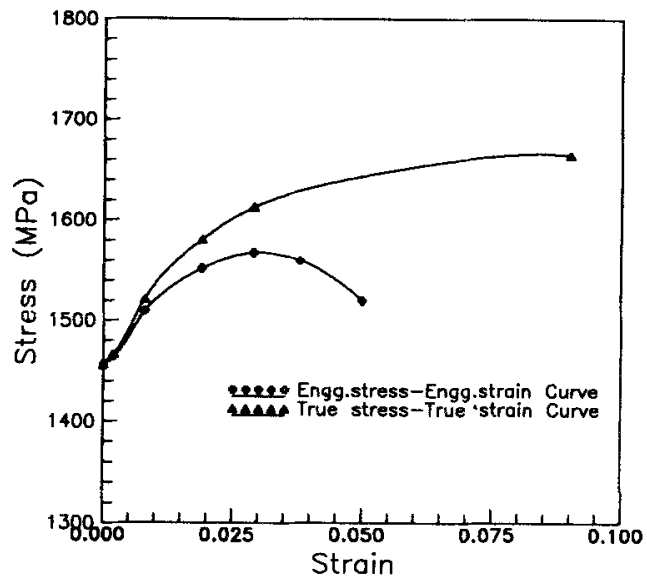

Figure 2. Tensile stress--strain curves for near-eutectoid stecl: (a) Normalized, (b) hardened and tempered at $680^{\circ} \mathrm{C}$ for $1 \mathrm{~h}$, (c) furnace cooled and (d) hardened and tempered at $500^{\circ} \mathrm{C}$ for $1 \mathrm{~h}$. 
dispersion strengthening effect of particles depends on their size and spacing. The coarsening of cementite particles causes a softening of the steel at higher tempering temperature as seen in the case of treatment 2 (tempering at $680^{\circ} \mathrm{C}$ for $1 \mathrm{~h}$ ). On the other hand, higher strength obtained for treatment 4 (tempering at $500^{\circ} \mathrm{C}$ for $1 \mathrm{~h}$ ) results from the ultrafine cementite particles.

The true stress-true strain curves of samples subjected to different heat treatments are shown in figure 2 and it may be noted that the true stress-true strain values of the last point of these stress-strain curves are based
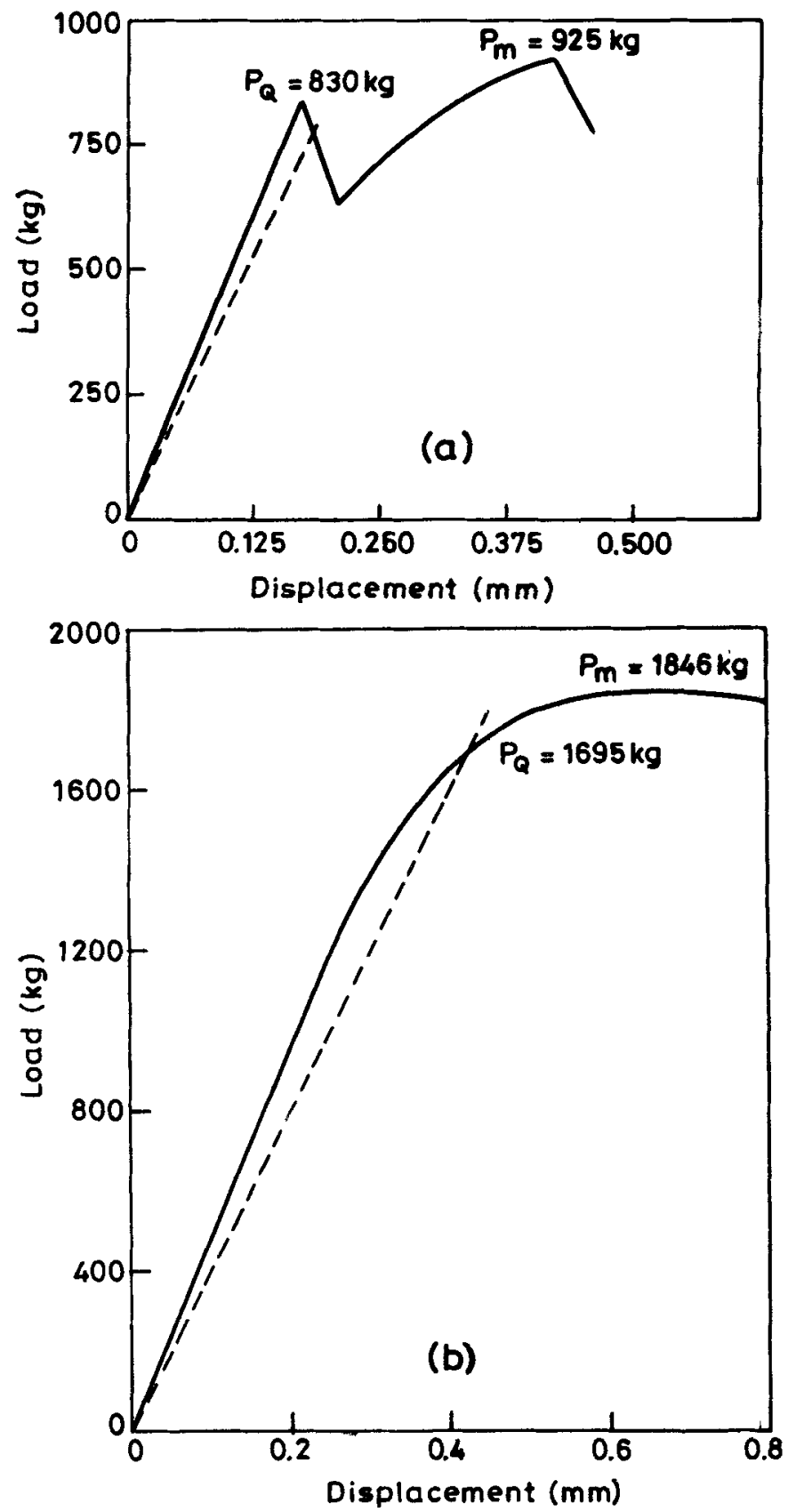

Figure 3. Typical load-displacement (COD) curves for neareutectoid steel: (a) Normalized and (b) hardened and tempered at $680^{\circ} \mathrm{C}$ for $1 \mathrm{~h}$. on the percent reduction in area at fracture. On checking the validity of plane strain condition in fracture toughness tests, the plane strain condition is valid only for the normalized (treatment 1) and tempered at $500^{\circ} \mathrm{C}$ for $1 \mathrm{~h}$ (treatment 4) cases. For fracture toughness tests involving the other two heat treatments, the condition of plane strain is not valid. Thus quantitative comparison of fracture toughness is possible for treatments 1 and 4 only but not for 2 and 3 . Considering the treatments 1 and 4 , the yield strength of the tempered $\left(500^{\circ} \mathrm{C}\right)$ specimen is nearly twice that of the normalized one. It can be noted that despite the increase in strength, the fracture toughness of tempered $\left(500^{\circ} \mathrm{C}\right.$ for $\left.1 \mathrm{~h}\right)$ specimen is significantly higher than that of normalized one. Thus the tempered $\left(500^{\circ} \mathrm{C}\right.$ for $\left.1 \mathrm{~h}\right)$ specimen exhibits simultaneous increase in strength and toughness relative to the normalized treatment. The usual inverse relation between strength and toughness is not applicable while comparing the properties arising from these heat treatments. The higher toughness of the tempered $\left(500^{\circ} \mathrm{C}\right.$
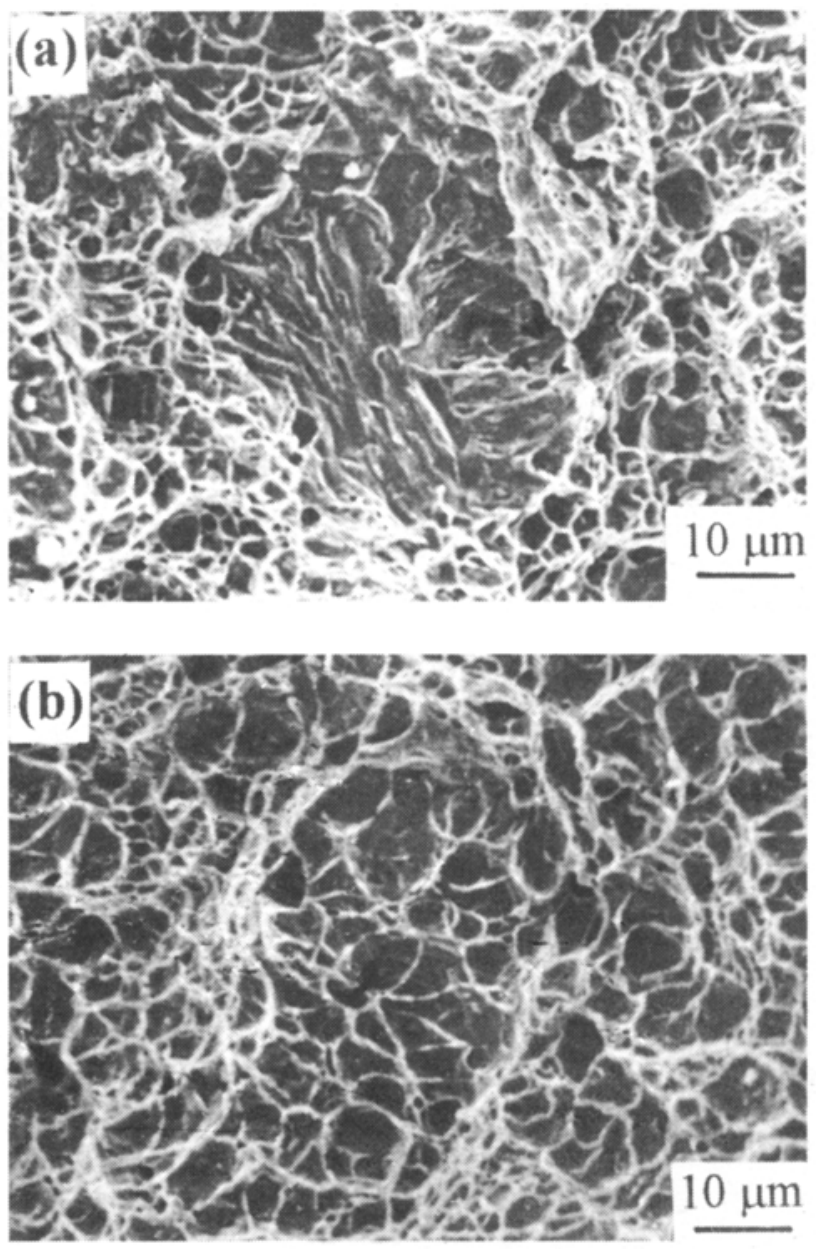

Figure 4. Typical SEM fractographs for near-eutectoid steel: (a) Normalized and (b) hardened and tempered at $680^{\circ} \mathrm{C}$ for I h. 
Table 4. Charpy test data of heat treated specimens.

\begin{tabular}{|c|c|c|c|c|}
\hline \multirow{2}{*}{$\begin{array}{l}\text { SI } \\
\text { no. }\end{array}$} & \multirow[b]{2}{*}{ Heat treatment ${ }^{+}$} & \multicolumn{2}{|c|}{ Charpy energy $\left(C_{\mathrm{v}}\right)$} & \multirow{2}{*}{$\begin{array}{l}\text { Equivalent } K_{\mathrm{K}}^{*} \\
(\mathrm{MPa} \sqrt{m})\end{array}$} \\
\hline & & $\left(\mathrm{J} / \mathrm{cm}^{2}\right)$ & (MPa'm) & \\
\hline 1. & Normalized & 13.6 & 0.136 & 48 \\
\hline 2. & $\begin{array}{l}\text { Oil hardened and tempered } \\
\text { at } 680^{\circ} \mathrm{C} \text { for } 1 \mathrm{~h}\end{array}$ & $44 \cdot 7$ & 0.447 & 117 \\
\hline 3. & Furnace cooled & $16 \cdot 3$ & 0.163 & 55 \\
\hline 4. & $\begin{array}{l}\text { Oil hardened and tempered } \\
\text { at } 500^{\circ} \mathrm{C} \text { for } 1 \mathrm{~h}\end{array}$ & 21.7 & 0.217 & 68 \\
\hline
\end{tabular}

+Obtained from equation (2); ${ }^{+}$all austenitized at $860^{\circ} \mathrm{C}$.

for $1 \mathrm{~h}$ ) specimen follows from the tempered martensitic structure. The carbides are expected to be mostly spherical in shape and they arrest the crack propagation through their fine distribution. On the other hand, the normalized treatment results in pearlitic structure. In this case the cementite platelets and/or cementite-ferrite interfaces provide easy path for crack propagation (Curry and Knott 1978; Porter et al 1978; Rama Rao 1978). Thus the tempered martensitic structure provides strengthening through the presence of ultrafine particles of cementite in ferrite and better toughness because the finely-dispersed carbides arrest crack propagation.

Fractographic observations of normalized and furnace cooled specimens indicate the presence of quasi-cleavage facets and dimples (figure 4a). A change in plane of fracture from one grain to the other can also be noted in the cleavage dominated regions. The path of the main crack might have been the cementite platelets or the interface between cementite and ferrite lamellae of the pearlitic microstructure. These easy paths of cleavage fracture lead to low value of fracture toughness.

In the tempered steels, fracture occurred predominantly by nucleation, growth and coalescence of voids. Microvoids are usually initiated at oxide and sulphide inclusions, carbides and other imperfections. The carbide particles assist the void formation by providing weak interfaces which separate in tensile loading. The particles may also fracture and the fractured parts move apart by plastic flow of the matrix. The individual voids thus formed join together by local necking of ligaments between the voids and there is some plastic flow before fracture occurs. This process is associated with more energy absorption and, thus, a higher toughness.

\subsection{Correlation between fracture toughness and other mechanical properties}

The estimates of $K_{\mathrm{IC}}$ from the tensile and impact test data are shown in tables 2 and 4 , respectively. Considering the toughness estimates from tensile tests, one to one correlation is not seen between them and the apparent toughness $\left(K_{\mathrm{Q}}\right)$ measured directly. However, the trends of change in toughness with heat treatment are similar. On comparing the $K_{\mathrm{Q}}$ data obtained from fracture toughness tests with those estimated from the impact energy values, good quantitative agreement can be noted between them.

\section{Conclusions}

(I) From a comparison between yield strength and fracture toughness of specimens with similar microstructures, the toughness is seen to decrease with the increase in strength. (II) The hardened and tempered $\left(500^{\circ} \mathrm{C}\right.$ for $\left.1 \mathrm{~h}\right)$ treatment results in two-fold increase in strength with a significant increase in fracture toughness relative to the normalized one. The fine particles of cementite in ferrite cause strengthening and also arrest the crack propagation and thereby enhance the fracture toughness. On the other hand, the pearlitic microstructure is of lower strength and it provides easy paths for crack propagation along the cementite platelets and/or cementite/ferrite interfaces. (III) The variation in fracture toughness values deduced indirectly from tensile tests follow the same qualitative trend as those directly measured for different heat treatments, but the two sets of values differ from each other. On the other hand, the fracture toughness data obtained from charpy tests is in closer agreement with that measured directly for different heat treatments.

\section{References}

Curry D A and Knott J F 1978 Metal Sci. 8511

Hahn G T and Rosenfield A R 1968 ASTM STP 4325

Porter D A, Easterling K E and Smith G D W 1978 Acta Metall. 261405

Provan J W 1988 J. Mater. Edu. 10325

Rama Rao P 1978 Trans. Indian Inst. Metals 31239

Rolfe S T and Novak S R 1970 ASTM STP 463124 